\title{
Gating of Transient Receptor Potential Melastatin 8 (TRPM8) Channels Activated by Cold and Chemical Agonists in Planar Lipid Bilayers
}

\author{
Eleonora Zakharian, Chike Cao, and Tibor Rohacs \\ Department of Pharmacology and Physiology, University of Medicine and Dentistry of New Jersey-New Jersey Medical School, Newark, New Jersey 07103
}

\begin{abstract}
The transient receptor potential melastatin 8 (TRPM8) ion channel is a major sensor of environmental cold temperatures. It is activated by cold and chemical agonists, such as menthol and icilin. The activation of these channels both by cold and cooling agents requires the presence of the membrane phospholipid phosphatidylinositol 4,5-bisphosphate $\left[\mathrm{PI}(4,5) \mathrm{P}_{2}\right]$. The mechanism of TRPM8 activation by physical and chemical factors is unknown, and the involvement of cellular signaling pathways has been considered. Here we have characterized the gating mechanism of the rat TRPM8 reconstituted in planar lipid bilayers and its activation by different stimuli. In this system, the influence of cellular signaling pathways can be excluded. We found that TRPM8 activated by cold exhibits steep temperature dependence [temperature coefficient $\left(Q_{10}\right)$ of $\sim 40$ ], and the channel openings are accompanied by large changes in entropy and enthalpy, suggesting a substantial conformation change. TRPM8 channel behavior upon menthol and icilin activation was distinguishable, and the effect of icilin depended on the presence of calcium on the intracellular side of the protein. Here we also demonstrate that $\mathrm{PI}(4,5) \mathrm{P}_{2}$ is the prime factor that impacts the gating of TRPM8 and that other phosphoinositides are less efficient in supporting channel activity. Menthol increases the potency of $\mathrm{PI}(4,5) \mathrm{P}_{2}$ to activate the channels and increases binding of phosphoinositides to the full-length channel protein. Our data demonstrate conclusively that TRPM8 is gated by cold and its chemical agonists directly, and that dependence of its gating on $\mathrm{PI}(4,5) \mathrm{P}_{2}$ is a result of direct specific interactions with the lipid.
\end{abstract}

\section{Introduction}

Transient receptor potential melastatin 8 (TRPM8) channels are activated by cold and chemical compounds such as menthol and icilin (McKemy et al., 2002; Peier et al., 2002). TRPM8 is widely accepted to be a major sensor of environmental cold temperatures (Bautista et al., 2007; Colburn et al., 2007; Dhaka et al., 2007). Although, it was originally assumed that TRPM8 channels are activated by cold and the chemical agonists directly, several independent articles challenged this view by showing that TRPM8 activation could be prevented by inhibition of the phospholipase $\mathrm{A}_{2}\left(\mathrm{PLA}_{2}\right)$ pathway (Abeele et al., 2006; Andersson et al., 2007; Gentry et al., 2010). To examine whether the TRPM8 agonists exert their effects on the channel directly, we have characterized the regulation of TRPM8 gating in a reconstituted system using planar lipid bilayers.

The activity of TRPM8 was shown to depend on the presence of phosphatidylinositol-4,5-bisphosphate $\left[\mathrm{PI}(4,5) \mathrm{P}_{2}\right]$ in cellular systems (Liu and Qin, 2005; Rohács et al., 2005; Daniels et al., 2009). $\mathrm{PI}(4,5) \mathrm{P}_{2}$ has emerged as a general regulator of ion chan-

Received June 21, 2010; revised July 28, 2010; accepted July 30, 2010.

This work was supported by National Institutes of Health Grant NS055159 and a grant from the University of Medicine and Dentistry of New Jersey Foundation to T.R., and a Scientist Development Grant from the American Heart Association to E.Z.

Correspondence should be addressed to Tibor Rohacs, Department of Pharmacology and Physiology, University of Medicine and Dentistry of New Jersey, New Jersey Medical School, Newark, New Jersey 07103; E-mail: rohacsti@umdnj.edu.

DOI:10.1523/JNEUROSCI.3189-10.2010

Copyright $\odot 2010$ the authors $\quad 0270-6474 / 10 / 3012526-09 \$ 15.00 / 0$ nels (Hilgemann et al., 2001). It is believed to activate ion channels through interactions with positively charged residues in the cytoplasmic tails of various ion channels. Despite the large number of ion channels being activated by this lipid (Suh and Hille, 2008), a definitive proof for direct activation by $\mathrm{PI}(4,5) \mathrm{P}_{2}$ is lacking.

TRPM8 channels exhibit highly complicated gating behavior that is regulated by a variety of factors. In addition to the functional complexity of TRPM8, our recent findings indicate that the channel itself exists as a complex, where it is chemically and functionally modified by inorganic polyphosphate (polyP) and polyhydroxybutyrate (PHB) (Zakharian et al., 2009). In that article (Zakharian et al., 2009), we demonstrated that polyP modulates TRPM8 channels directly, using the purified protein from mammalian cells incorporated in planar lipid bilayers. This system also allowed us the preliminary characterization of the functional features of the reconstituted TRPM8, showing that it is activated by menthol and cold in the presence of $\mathrm{PI}(4,5) \mathrm{P}_{2}$.

In the present study, we performed detailed biophysical characterization of TRPM8 channels that were obtained from two different expression systems, mammalian and bacterial. We show that the channel is activated by cold temperatures with a steep temperature dependence [temperature coefficient $\left(Q_{10}\right)$ of $\sim 40$ ]. The purified TRPM8 is also gated by icilin, demonstrating that this chemical compound exerts its effects directly on the channel protein. The effect of icilin was essentially eliminated by chelating $\mathrm{Ca}^{2+}$ from the intracellular side of the protein. Activation by cold and the cooling agents depended specifically on the presence of 
$\mathrm{PI}(4,5) \mathrm{P}_{2}$ in the lipid bilayers; other phosphoinositides were less effective. The apparent affinity of the purified channel protein for $\mathrm{PI}(4,5) \mathrm{P}_{2}$, both in functional measurements and in biochemical binding, was enhanced by increased menthol concentrations. Our data conclusively demonstrate that cold, menthol, and icilin activate TRPM8 directly in the context of the lipid bilayer in the presence of $\mathrm{PI}(4,5) \mathrm{P}_{2}$.

\section{Materials and Methods}

Cell culture. HEK-293 cells were maintained in MEM solution (Invitrogen) supplemented with $10 \%$ fetal bovine serum (Invitrogen) and $1 \%$ penicillin/streptomycin. The cells were transfected with the rat TRPM8 cDNA using the Effectene reagent (Qiagen). The TRPM8 stable cell line was developed with TRPM8 tagged with $m y c$ on the $\mathrm{N}$ terminus and with 6 -His residues on the $\mathrm{C}$ terminus, as previously described (Zakharian et al., 2009).

Preparation of the TRPM8 protein from HEK cells. HEK-293 cells stably expressing TRPM 8 were grown to $70-80 \%$ confluence, washed, and collected with cold PBS. Cells were harvested and resuspended in NCB buffer, containing $500 \mathrm{~mm} \mathrm{NaCl}, 50 \mathrm{~mm} \mathrm{NaH}_{2} \mathrm{PO}_{4}, 20$ mM HEPES, $2 \mathrm{~mm}$ $\mathrm{Na}$-orthovanadate, $10 \%$ glycerol, $20 \mathrm{~mm}$ imidazole, $\mathrm{pH} 7.5$, with addition of $1 \mathrm{~mm}$ protease inhibitor PMSF, and $5 \mathrm{~mm} \beta$-mercaptoethanol. Then the cells were lysed by the freeze-thawing method and centrifuged at low speed to remove cell debris and DNA. The supernatant was further centrifuged at $40,000 \times g$ for $2 \mathrm{~h}$, and the pellet was resuspended in NCB buffer with addition of a protease inhibitor mixture (Roche), $20 \mu \mathrm{g} / \mathrm{ml}$ DNase, $20 \mu \mathrm{g} / \mathrm{ml}$ RNase, $0.1 \%$ Nonidet P-40 (Roche), and 0.5\% dodecylmaltoside (DDM) (CalBiochem). The suspension was incubated overnight at $4^{\circ} \mathrm{C}$ on a shaker with gentle agitation and then centrifuged for $1 \mathrm{~h}$ at $40,000 \times g$. Further, the TRPM8 protein was purified with ion-affinity chromatography using Ni-NTA magnetic beads (Qiagen), following the procedure provided by the manufacturer. All steps of purification were performed at $4^{\circ} \mathrm{C}$.

Preparation of the TRPM8 protein derived from bacterial expression. The plasmid pET21b, containing the His-tagged TRPM8 was transformed into Escherichia coli BL21(DE3)-competent cells (Invitrogen) and overexpressed by addition of $1 \mathrm{~mm}$ IPTG (isopropyl- $\beta$-D-thiogalactopyranoside) (Roche) at $20^{\circ} \mathrm{C}$ overnight. Cells were collected in $20 \mathrm{~mm}$ Tris- $\mathrm{HCl} \mathrm{pH}$ 7.5, 10 mм EDTA, $0.1 \%$ Triton X-100 with addition of 1 mм PMSF, 20 $\mu \mathrm{g} / \mathrm{ml}$ lysozyme, $20 \mu \mathrm{g} / \mathrm{ml}$ DNase, and $20 \mu \mathrm{g} / \mathrm{ml}$ RNase, and lysed by ultrasonic disintegration. Inclusion bodies (IBs) were isolated in $20 \mathrm{~mm}$ Tris- $\mathrm{HCl}$ pH 7.5, 10 mm EDTA, 1\% Triton X-100, and then washed three times in the same buffer, collecting the pellet by centrifugation at $10,000 \times g$ for $15 \mathrm{~min}$. The last pellet of the IB was resuspended in LCB buffer, containing $400 \mathrm{~mm} \mathrm{LiCl,} 1 \mathrm{~mm} \mathrm{MgCl} 2,15 \%$ glycerol, $20 \mathrm{~mm}$ HEPES, $\mathrm{pH}$ 7.5, and protease-inhibitor mixture tablets (Complete Mini, Roche). Further, the recombinant TRPM8 (rTRPM8) protein was extracted with $0.5 \% \mathrm{DDM}$ (CalBiochem) and purified with ion-affinity chromatography using Ni-NTA beads (Qiagen) following the procedure provided by the manufacturer. At last, to refine the homogeneity of the TRPM8 protein we performed gel-filtration chromatography using a Superdex-200 column $(1.6 \times 60 \mathrm{~cm})$ (GE Healthcare). TRPM8 was eluted with LCB buffer in the presence of 2 mM DDM.

SDS-PAGE. Proteins were electrophoretically separated with $10 \%$ SDS-PAGE (Bio-Rad) using Tris-glycine SDS buffer (Bio-Rad) at a constant voltage of $185 \mathrm{~V}$. The electrophoresis buffer for the native gels did not contain SDS. Protein bands were visualized by staining with Silver Stain or Coomassie Brilliant Blue R-250 (Bio-Rad). For Western blot analysis, protein was transferred onto polyvinylidene difluoride membranes (Bio-Rad) in $10 \mathrm{~mm} 3$-(cyclohexylamino)-1-propanesulfonic acid and $0.07 \%$ SDS buffer at $30 \mathrm{~V}$ overnight. The TRPM8 protein was detected with anti-Myc-IgG (Sigma) or with anti-CMR-1-IgG antibodies (Phoenix Pharmaceuticals).

Determination of polyP. PolyP was visualized on the native $10 \%$ polyacrylamide-ready gels from Bio-Rad. Electrophoresis was performed at $100 \mathrm{~V}$ for $1-1.5 \mathrm{~h}$. Gels were incubated for $1 \mathrm{~h}$ in a fixative solution consisting of $25 \%$ methanol $/ 5 \%$ glycerol, stained for 30 min with $0.05 \%$ $o$-toluidine blue, and destained in a fixative for $2 \mathrm{~h}$.
PIP strips assay. PIP strips (Echelon Biosciences) were blocked for $1 \mathrm{~h}$ in $1 \%$ fatty-acid free bovine serum albumin (BSA) in Tris buffer saline in the presence of $0.06 \%$ Tween (TTBS), then $20-25 \mu \mathrm{g} / \mathrm{ml}$ rTRPM8 protein was added to the strips and incubated at $4^{\circ} \mathrm{C}$ overnight with very gentle agitation. Further, the strips were washed 3 times with TTBS buffer and immunoblotted with anti-CMR-1 antibody (Phoenix Pharmaceuticals). Protein bound to the PIP strips was detected with Super-Signal West ECL kit (Pierce).

Planar lipid bilayer measurements. Planar lipid bilayers were formed from a solution of synthetic 1-palmitoyl-2-oleoyl-glycero-3-phosphocoline (POPC) and 1-palmitoyl-2-oleoyl-glycero-3-phosphoethanolamine (POPE) (Avanti Polar Lipids) in a 3:1 ratio in $N$-decane (Aldrich). The solution was used to paint a bilayer in an aperture of $\sim 150 \mu \mathrm{m}$ diameter in a Delrin cup (Warner Instruments) between symmetric aqueous bathing solutions of $150 \mathrm{~mm} \mathrm{KCl}$ and $20 \mathrm{~mm} \mathrm{HEPES,} \mathrm{pH} 7.2$, at $22^{\circ} \mathrm{C}$. All salts were ultrapure ( $>99 \%$ ) (Aldrich). Bilayer capacitances were in the range of 50-75 pF. After the bilayers were formed, $0.2 \mu \mathrm{l}$ of the TRPM8 micellar solution $(0.002 \mu \mathrm{g} / \mathrm{ml})$ was added to the cis compartment with gentle stirring. Unitary currents were recorded with an integrating patch-clamp amplifier (Axopatch 200A, Molecular Devices). The trans solution (voltage command side) was connected to the CV 201A head-stage input, and the cis solution was held at virtual ground via a pair of matched $\mathrm{Ag}-\mathrm{AgCl}$ electrodes. Currents through the voltage-clamped bilayers (background conductance, $<3$ $\mathrm{pS}$ ) were filtered at the amplifier output (low pass, $-3 \mathrm{~dB}$ at $10 \mathrm{kHz}$, 8-pole Bessel response). Data were secondarily filtered at $100 \mathrm{~Hz}$ through an eight-pole Bessel filter (950 TAF, Frequency Devices) and digitized at $1 \mathrm{kHz}$ using an analog-to-digital converter (Digidata 1322A, Molecular Devices) controlled by pClamp9 software (Molecular Devices). Single-channel conductance events, all-point histograms, open probabilities, and other parameters were identified and analyzed using the Clampfit9 software (Molecular Devices). Experiments were performed at room temperature $\sim 22^{\circ} \mathrm{C}$, except for the temperature studies.

Temperature studies. For temperature studies, a Delrin cuvette was seated in a bilayer recording chamber made of a thermally conductive plastic (Warner Instruments). The chamber was fitted on a conductive stage containing a pyroelectric heater/cooler. Deionized water was circulated through this stage, pumped into the system to remove the heat generated. The pyroelectric heating/cooling stage was driven by a temperature controller (CL-100, Warner Instruments). The temperature of the bath was monitored constantly with a thermoelectric device in the cis side (i.e., the ground side of the cuvette). Although there was a temperature gradient between the bath solution and conductive stage, the temperature within the bath could be reliably controlled within $\pm 0.5^{\circ} \mathrm{C}$.

The $Q_{10}$ for single-channel conductance, or for $P_{\mathrm{o}}$, was obtained from the following equation:

$$
Q_{10}=\left(\frac{X_{2}}{X_{1}}\right)^{\frac{10}{T_{2}-T_{1}}}
$$

Energies of activation $\left(E_{\mathrm{a}}\right)$ were calculated from the Arrhenius equation, or directly from the slope of the Arrhenius plot:

$$
E_{\mathrm{a}}=\frac{R T_{1} T_{2}}{T_{2}-T_{1}} \ln \frac{X_{2}}{X_{1}}
$$

where $R$ is the gas constant $(8.314 \mathrm{~J} / \mathrm{mol})$, and $T_{1}$ and $T_{2}$ are temperatures in kelvins.

\section{Results}

To study TRPM 8 channels in planar lipid bilayers, we purified the protein from HEK-293 cells stably expressing the his-tagged TRPM8, using ion-affinity chromatography (see Materials and Methods) (supplemental Fig. 1, available at www.jneurosci.org as supplemental material). After each protein purification procedure, we also examined TRPM8 on native gels to confirm the 

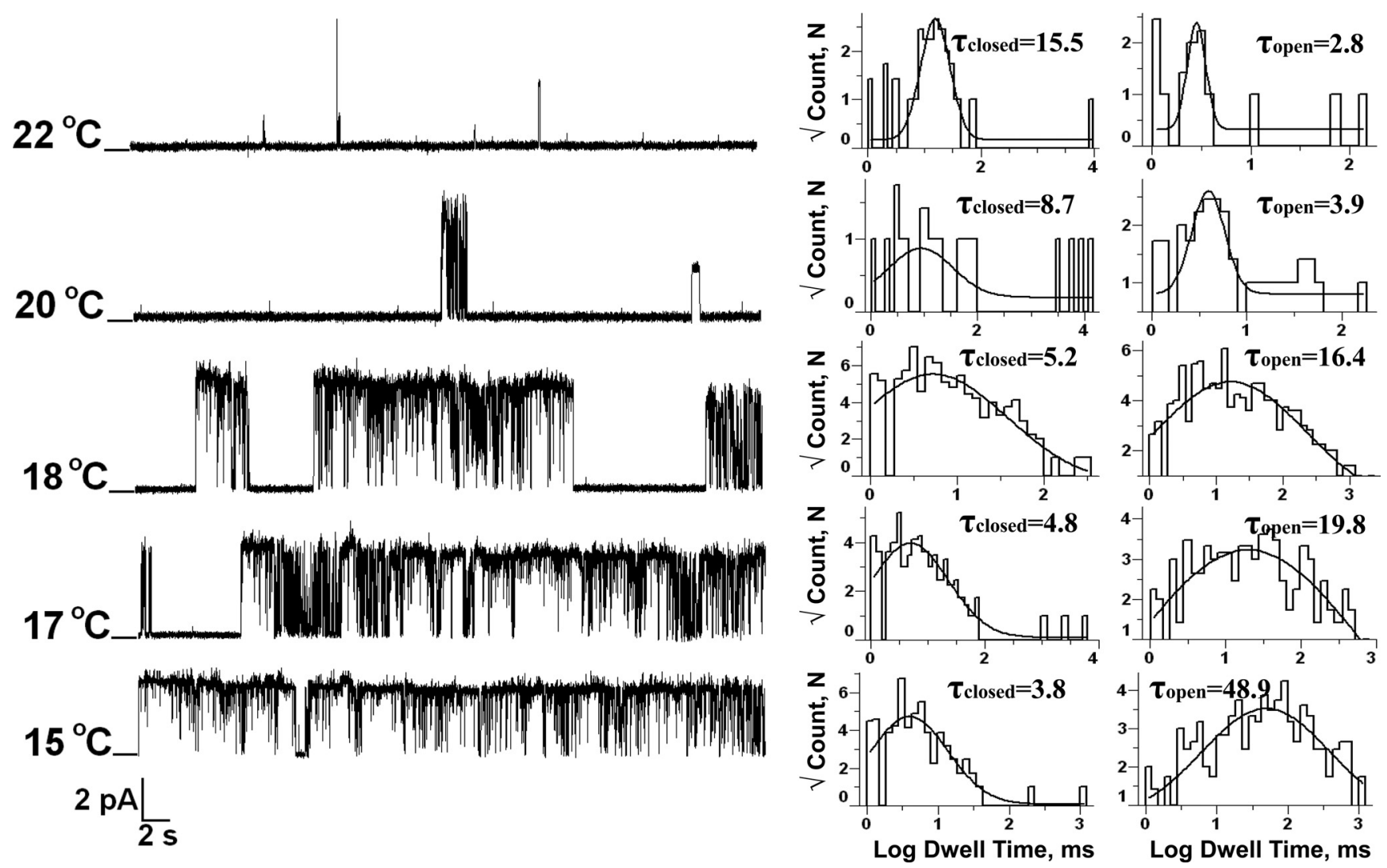

Figure 1. Cold activation of TRPM 8 channels in planar lipid bilayer. Representative single-channel current recordings and dwell-time histograms of TRPM 8 channels activated by cold in the presence of $2.5 \mu \mathrm{M} \mathrm{diC}{ }_{8} \mathrm{PI}(4,5) \mathrm{P}_{2}$ : TRPM8 channels incorporated in planar lipid bilayers formed from POPC/POPE (3:1) in N-decane, between symmetric bathing solutions of 150 mM KCl and 0.2 mM $\mathrm{MgCl}_{2}$ in $20 \mathrm{~mm}$ HEPES buffer, pH 7.2. The purified TRPM8 protein ( $\left.0.2 \mu \mathrm{lof} 0.002 \mu \mathrm{g} / \mathrm{ml}\right)$ incorporated in POPC/POPE micelles was added to the cis compartment (ground). Clamping potential was $+100 \mathrm{mV}$. Data were filtered at $100 \mathrm{~Hz}$. Left, Representative single-channel traces obtained at the temperatures values as indicated on the left. The dwell-time histograms for closed and open states, corresponding to the representative traces, are shown on the right, along with time constants for the closed and open states, calculated from the peaks of the Boltzmann distribution.

presence of polyP (supplemental Fig. 1C, available at www. jneurosci.org as supplemental material), the polymer that is required for TRPM8 channel function (Zakharian et al., 2009).

\section{TRPM8 channel properties upon cold activation}

Recently, we have demonstrated that TRPM8 channels can be activated by cold temperatures in planar lipid bilayers (Zakharian et al., 2009). Here we performed a detailed analysis of this activation. Figure 1 shows representative current traces of TRPM8 obtained at different temperatures and corresponding mean closed and open times. We found that upon decreasing the temperature of the bilayer system, TRPM8 demonstrates a significant change in the open probability of the channel (Figs. 1, 2A). In the temperature range between 21 and $18^{\circ} \mathrm{C}$, the channel open probability at $100 \mathrm{mV}$ shifted dramatically from $\sim 0.04$ to $\sim 0.89$, as the long closures rapidly decreased in their duration. The increase of $P_{\mathrm{o}}$ was sigmoidal with a steep slope, negligible activity at $>21^{\circ} \mathrm{C}$, and exhibited saturation at $<18^{\circ} \mathrm{C}$ (Fig. $2 \mathrm{~A}$ ). Thermodynamic analysis provided the values for the temperature coefficient of TRPM8 activation. We plotted the $\log$ of $P_{\mathrm{o}}$ values versus temperature and obtained two temperature-dependent components of the activation (Fig. $2 B$ ). One phase, although deviated from the linearity of the Arrhenius plot, exhibited high temperature sensitivity with $Q_{10}=40.1 \pm 13.5$ in the range between 26 and $18^{\circ} \mathrm{C}$ and a second shallow phase with $Q_{10}=1.6 \pm 0.15$ in the range between 18 and $15^{\circ} \mathrm{C}$. Their energies of activation were 262 and $21 \mathrm{~kJ} / \mathrm{mol}$, respectively. In Figure $2 C$, the data with $P_{\mathrm{o}}$ were fitted in the Van't Hoff plot that represents the relationship of $\ln \left(K_{\text {eq }}\right)$ versus $1 / T$, where the equilibrium constant, $K_{\text {eq }}$, was determined as $K_{\mathrm{eq}}=P_{\mathrm{o}} /\left(1-P_{\mathrm{o}}\right)$. Since $\ln \left(K_{\mathrm{eq}}\right)=-(\Delta H / R T)+(\Delta S /$ $R)$, the values for change in enthalpy and entropy can be obtained from the linear fit of the plot, which again demonstrated two phases for the temperature dependence of TRPM8. The best linear fit for the higher temperatures was obtained for the region, where the main shift in the openings of TRPM8 was observed, between 23 and $18^{\circ} \mathrm{C}$. It exhibited large transitional changes of enthalpy and entropy with $\Delta H=-792.8 \mathrm{~kJ} / \mathrm{mol}$ and $\Delta S=$ $-2.716 \mathrm{~kJ} / \mathrm{mol} \cdot \mathrm{K}$. After the activation, a second transitional phase is obtained for the temperature range between 18 and $15^{\circ} \mathrm{C}$, and it has $\Delta H=-262.2 \mathrm{~kJ} / \mathrm{mol}$ and $\Delta S=-0.886 \mathrm{~kJ} / \mathrm{mol} \cdot \mathrm{K}$. The two phases of temperature dependence of TRPM 8 activation and large negative values of enthalpy and entropy changes, but low free-energy change, obtained for TRPM8 (Fig. 2D) are in agreement with a previous report (Brauchi et al., 2004).

Figure $2 E$ demonstrates the change in the conductance of the outward and inward currents under the cooling conditions. The changes in conductance were also temperature sensitive and exhibited $Q_{10}$ of $3.2 \pm 0.16$ (Fig. $2 F$ ) and energy of activation equal to $82.7 \pm 3.7 \mathrm{~kJ} / \mathrm{mol}$ (supplemental Fig. S2, available at www. jneurosci.org as supplemental material). The values of $Q_{10}$ and $E_{\mathrm{a}}$ were averaged from the slopes of both outward and inward conductance.

The temperature analysis of TRPM8 was derived from at least 45 independent experiments, with 37,980 events analyzed. 

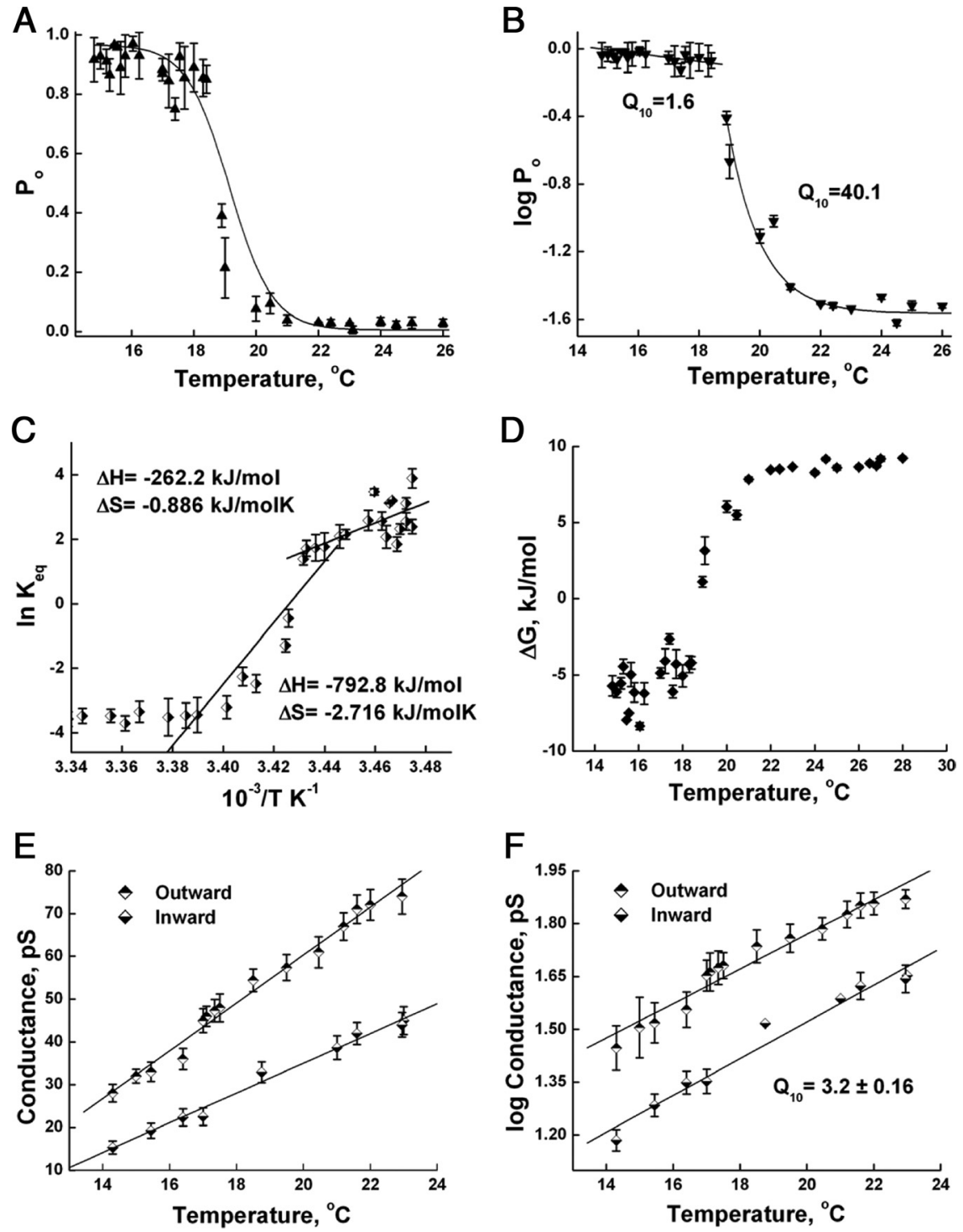

Figure 2. Thermodynamic analysis of TRPM8 open probability and conductance upon cold activation. $\boldsymbol{A}$, Open probability obtained during cooling the planar lipid bilayer. $\boldsymbol{B}$, Two phases of temperature dependence presented in $\log \left(P_{0}\right)$ versus $T$ plot. $\boldsymbol{C}$, Van't Hoff plot of the equilibrium constant $K_{\text {eq }}$ demonstrates two linear fits obtained in the range between 23 and $18^{\circ} \mathrm{C}$ and in the range between 18 and $15^{\circ} \mathrm{C}$, representing changes in enthalpy and entropy of temperature activation of TRPM8 channels. $\boldsymbol{D}$, Free-energy change, $\Delta G$, versus temperature plot. $\Delta G$ was calculated as $R T \times \ln \left(K_{\text {eq }}\right)$. $E$, TRPM 8 single-channel conductance for outward and inward currents obtained upon cold activation. $F$, Log of conductance versus temperature demonstrates the $Q_{10}$ value averaged for outward and inward currents, which was obtained from the regression slope. Energy of activation, $E_{\mathrm{a}}=82.7 \pm 3.7$ $\mathrm{kJ} / \mathrm{mol}$, was calculated from the slope of the Arrhenius plot as slope $=-E_{\mathrm{a}} / R$, and also was averaged from both slopes of outward and inward currents (supplemental Fig. S2, available at www.jneurosci.org as supplemental material). The temperature analysis of TRPM8 was derived from at least 45 independent experiments. All data are expressed as mean \pm SEM.

\section{Phosphoinositides regulate TRPM8 channel gating}

Macroscopic channel recordings obtained from excised patches show that the activity of TRPM8 depends on the presence of phosphoinositides (Liu and Qin, 2005; Rohács et al., 2005). To address whether the lipids exert their effects directly on the channel, we characterized TRPM8 channel properties in planar lipid bilayers. TRPM8 was activated by its major agonist — menthol $(500 \mu \mathrm{M})$ - in the presence of the following phosphoinositides: $2.5 \mu \mathrm{M} \mathrm{diC}{ }_{8} \mathrm{PI}(4) \mathrm{P}$, $\mathrm{PI}(3,4,5) \mathrm{P}_{2}, \mathrm{PI}(3,4) \mathrm{P}_{2}$, or $\mathrm{PI}(4,5) \mathrm{P}_{2}$. We found that with each particular phospholipid the channel demonstrated very different behavior, with the main alteration in the open probability (Fig. 3).

The least activity of the channel was observed in the presence of $\mathrm{PI}(4) \mathrm{P}$. In addition to the low open probability $\left(P_{\mathrm{o}}=0.122 \pm\right.$
0.0261 at $100 \mathrm{mV}$, and $P_{\mathrm{o}}=0.0189 \pm 0.01$ at $-100 \mathrm{mV} ; n=18$, number of events analyzed $=5403)($ Fig. 3B), TRPM8 channels activated by $\mathrm{PI}(4) \mathrm{P}$ exhibited openings only to a very small subconductance state with a magnitude of $4 \pm 0.56 \mathrm{pS}$ [compared with $72 \pm 12$ pS conductance of outward TRPM8 current obtained in the presence of $\left.\mathrm{PI}(4,5) \mathrm{P}_{2}\right]$ (Fig. $3 A$ ). All of the data were obtained in the gap-free recordings performed at -100 or $+100 \mathrm{mV}$.

Application of $\mathrm{PI}(3,4,5) \mathrm{P}_{2}$ in the presence of menthol resulted in higher activity of the channel with $P_{\mathrm{o}}=0.211 \pm 0.061$ obtained at $100 \mathrm{mV}$ and $P_{\mathrm{o}}=0.088 \pm$ 0.007 at $-100 \mathrm{mV}(n=7$, number of events analyzed $=2426)$ (Fig. 3 ). TRPM8 channels activated by $\mathrm{PI}(3,4,5) \mathrm{P}_{2}$ demonstrated very irregular gating behavior. More stable channel activity was observed in the presence of $\mathrm{PI}(3,4) \mathrm{P}_{2}$. Although in some recordings TRPM8 channels with $\mathrm{PI}(3,4) \mathrm{P}_{2}$ demonstrated very rapid gating transitions, still the channel activity and open probability were higher: $P_{\mathrm{o}}=$ $0.531 \pm 0.075$ at $100 \mathrm{mV}$ and $P_{\mathrm{o}}=0.2 \pm$ 0.05 at $-100 \mathrm{mV}(n=12$, number of events analyzed $=6627$ ) (Fig. 3 ).

The highest open probability and channel stability of TRPM8 were obtained in the presence of $\mathrm{PI}(4,5) \mathrm{P}_{2}$ (Fig. 3), with outward current $P_{\mathrm{o}}=0.89 \pm 0.075$ (at $100 \mathrm{mV}$ ) and inward current $P_{\mathrm{o}}=0.4 \pm$ 0.049 (at $-100 \mathrm{mV})(n=21$, number of events analyzed $=4719)$.

These experiments demonstrate that phosphoinositides alter TRPM8 channel gating and that the highest channel activity can be obtained with $\mathrm{PI}(4,5) \mathrm{P}_{2}$.

\section{Menthol sensitizes TRPM8 to $\mathrm{PI}(4,5) \mathrm{P}_{2}$ in lipid bilayers}

It was shown that both menthol and cold sensitize TRPM8 to $\mathrm{PI}(4,5) \mathrm{P}_{2}$ in excised patches (i.e., the $\mathrm{PI}(4,5) \mathrm{P}_{2}$ dose-response of TRPM8 activation shifts to the left) (Rohács et al., 2005). To study whether this functional characteristic of the channel regulation is retained in the purified TRPM8, we examined the concentration dependence of $\mathrm{PI}(4,5) \mathrm{P}_{2}$ activation in the presence of different menthol concentrations. Figure $4 A$ shows representative current traces of TRPM8 obtained at $100 \mathrm{mV}$ with 25 and $100 \mu \mathrm{M}$ menthol concentrations and five different concentrations of $\mathrm{PI}(4,5) \mathrm{P}_{2}$. The dose-response curves with three menthol concentrations presented in Figure $4 B$ (for $25 \mu \mathrm{M}$ menthol $n=12$, number of events analyzed at $100 \mathrm{mV}=5966$; for $100 \mu \mathrm{M}$ menthol $n=9$, number of events analyzed $=3233$; for $250 \mu \mathrm{M}$ menthol $n=10$, number of events $=1583)$. The results from these experiments demonstrate that $\mathrm{PI}(4,5) \mathrm{P}_{2}$ dose response, as a function of $P_{\mathrm{o}}$, shifts to the left as the menthol concentration increases. The $\mathrm{EC}_{50}$ values of TRPM8 for $\mathrm{PI}(4,5) \mathrm{P}_{2}$ were $5.6 \mu \mathrm{M}$ in the presence of $25 \mu \mathrm{M}$ menthol, $3.3 \mu \mathrm{M}$ in the presence of 
$100 \mu \mathrm{M}$ menthol, and $1.4 \mu \mathrm{M}$ in the presence of $250 \mu \mathrm{M}$ menthol. The apparent affinity of the channel for $\mathrm{PI}(4,5) \mathrm{P}_{2}$ in the bilayers was somewhat higher than that observed in excised patches (Rohács et al., 2005), indicating that the cellular environment modifies the effect of $\mathrm{PI}(4,5) \mathrm{P}_{2}$. Nevertheless, the sensitizing effect of menthol is preserved in the purified channel.

\section{Phosphoinositide binding to the TRPM8 protein}

We also studied biochemically the interaction of the TRPM8 protein with phosphoinositides, using PIP strips, the hydrophobic membranes that have been spotted with various biologically active lipids. The amounts of the TRPM8 protein, however, that can be purified from the mammalian cells are very small and limit analysis in biochemical assays. To overcome this problem, we subcloned the recombinant TRPM8 with His tag into a bacterial vector (rTRPM8), and purified the protein in comparably large amounts and with high purity by ion-affinity and gel-filtration chromatography techniques (Fig. 5A). To test whether the TRPM8 protein purified from bacteria was functional, we incorporated it in lipid bilayers. We found that the channel can be activated by its major agonists in the presence of $\mathrm{PI}(4,5) \mathrm{P}_{2}$ and behaves similarly to the TRPM8 protein that was obtained from the mammalian expression (Fig. $5 B, C$ ). Macroscopic currents of at least $9-10$ rTRPM8 channels, activated with $500 \mu \mathrm{M}$ menthol in the presence of $1 \% \mathrm{diC}_{16}$ $\mathrm{PI}(4,5) \mathrm{P}_{2}$, demonstrate the outward rectification characteristic to TRPM8 (Fig. $5 B$ ). Figure $5 C$ shows representative current traces and open probability of rTRPM8 activated by cold ( $n=7$, number of events analyzed $=$ 2756). These results indicate that the rTRPM8 protein derived from bacterial expression is functional and can be successfully used for further biochemical studies.

Next, we tested the binding of rTRPM8 to the PIP strips and found that the protein is binding to monophosphate, diphosphate, and triphosphate phosphoinositides and menthol significantly enhances this interaction $(n=7)$ (Fig. 5D).

\section{TRPM8 activation by icilin}

Icilin is a synthetic chemical compound that activates TRPM8 channels with high efficacy and potency (McKemy et al., 2002). Here we also studied TRPM8 channel activation by icilin in lipid bilayers. TRPM8 was incorporated in planar lipid bilayers in the presence of $2.5 \mu \mathrm{M} \mathrm{diC} 8 \mathrm{PI}(4,5) \mathrm{P}_{2}$ and then was activated with 1 $\mu \mathrm{M}$ icilin. Interestingly, we found that the rectification of TRPM8 currents, observed upon activation with menthol or cold that was determined by the low open probability and smaller conductance state of the inward currents (Zakharian et al., 2009), is no longer present when TRPM8 is activated by icilin (Fig. 6). The latter is
B

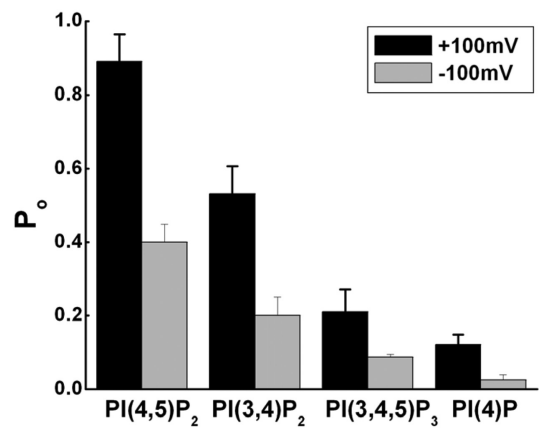

Figure 3. Specificity profile of phosphoinositide activation of TRPM8 channels in planar lipid bilayers. $A$, Representative singlennel current recordings of TRPM8 channels incorporated in planar lipid bilayers at $22^{\circ} \mathrm{C}$. TRPM8 channels were activated with described in the legend to Figure 1. Clamping potential was $+100 \mathrm{mV}$. B S Statistics of TRPM8 open probability obtained with the nositides. Open probability of TRPM8 channels operating in inward and outward directions measured at +100

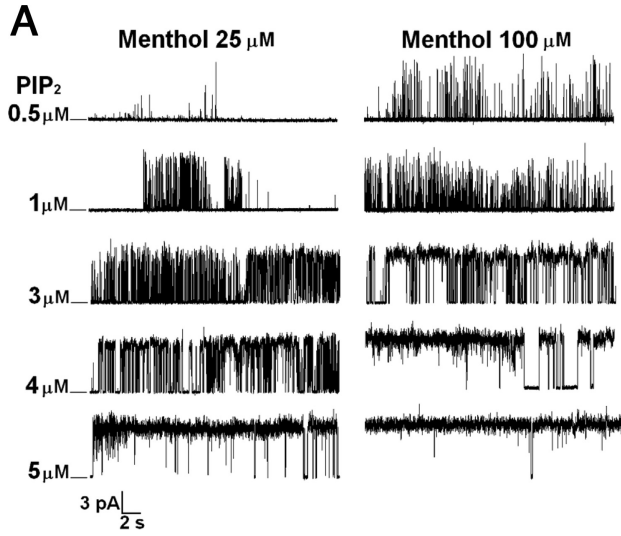

B

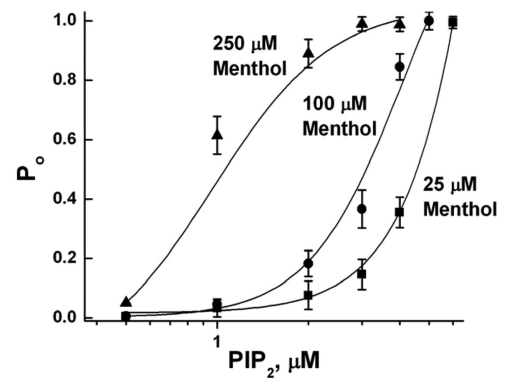

Figure 4. Concentration dependence of the effect of $\mathrm{PI}(4,5) \mathrm{P}_{2}$ on the open probability of TRPM8. $A$, Representative -channel current recordings of TRPM8 obtained in the presence of 25 and $100 \mu \mathrm{m}$ menthol concentrations upon 列 values of TRPM8 channels versus $\mathrm{PI}(4,5) \mathrm{P}_{2}$ concentration. Demonstrated $P_{0}$ values were obtained at $100 \mathrm{mV}$. Data were analyzed from a total of 31 experiments.

consistent with less rectifying icilin-induced TRPM8 currents observed in a cellular system (Rohács et al., 2005). In the reconstituted system, the channels were fully open to the magnitude of $74 \pm 10 \mathrm{pS}$ with $P_{\mathrm{o}}=0.98$ in both outward and inward directions. Figure $6 \mathrm{~A}$ demonstrates representative current traces of TRPM8 with inward currents presented at negative voltages and outward currents at positive voltages. The current/voltage relationship of icilin-induced TRPM8 currents is demonstrated in Figure $6 B$, and the distribution of open probabilities versus voltage is shown in Figure $6 C(n=13$, number of events analyzed $=17,082)$. It has been shown that full activation of TRPM8 channels with icilin requires elevated cytoplasmic $\mathrm{Ca}^{2+}$ concentrations (McKemy et al., 2002; Chuang et al., 2004). Our experiments with icilin were performed in solutions without added $\mathrm{Ca}^{2+}$ and without any $\mathrm{Ca}^{2+}$ buffers. In such solutions, free $\mathrm{Ca}^{2+}$ concentration is usually in the low micromolar range, which corresponds to elevated cytoplasmic $\mathrm{Ca}^{2+}$ concentrations. To study the dependence of the effect of icilin, we performed further experiments where we chelated $\mathrm{Ca}^{2+}$ with EGTA. Consistent with the $\mathrm{Ca}^{2+}$ dependence of the effect of icilin, we found that in the presence of $500 \mu \mathrm{M}$ 
A

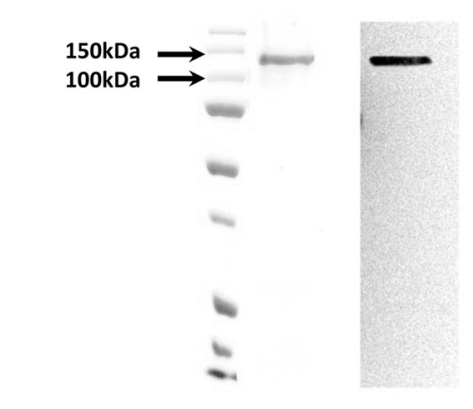

B

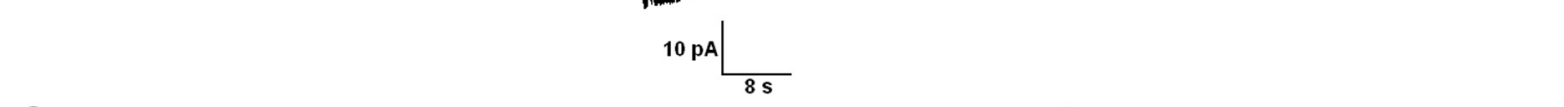

C

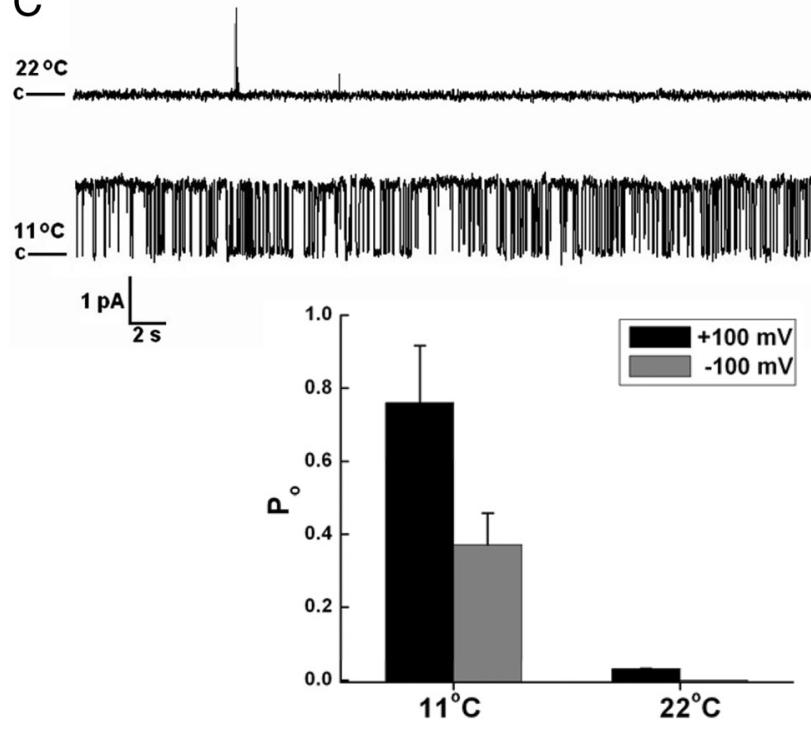

D

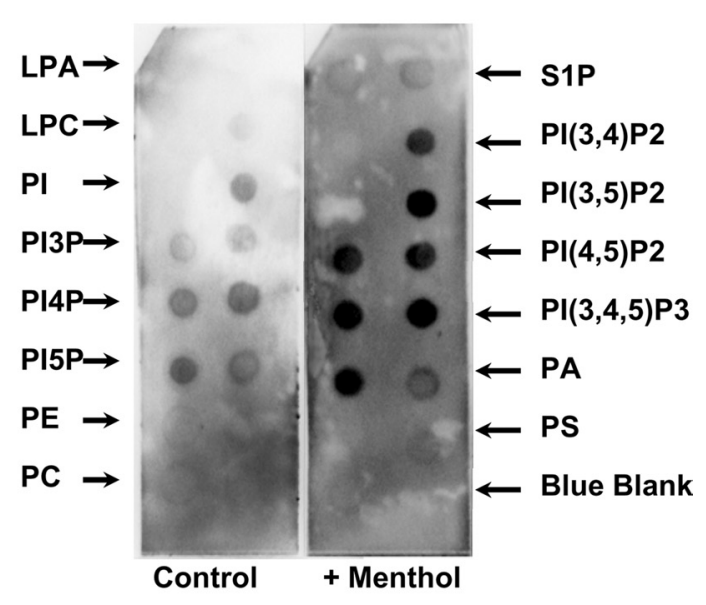

Figure 5. The rTRPM8 protein purified from bacteria forms functional channels in lipid bilayers, and binds phosphoinositides. A, A 10\% SDS-PAGE stained with Coomassie Blue and Western blot of rTRPM8 purified from DE3 BL21 competent cells: the left panel demonstrates the purified rTRPM8 protein detected with Coomassie staining; the right panel shows rTRPM8 on the Western blot that was detected with anti-CMR IgG. The protein bands have been observed at an apparent molecular weight of $\sim 129 \mathrm{kDa}$, which corresponds to a monomer of rTRPM8, including the His-tag. $\boldsymbol{B}$, rTRPM8 macroscopic currents recording in planar lipid bilayer, obtained upon activation with $500 \mu \mathrm{m}$ menthol in the presence of $1 \% \mathrm{diC}_{16} \mathrm{PI}(4,5) \mathrm{P}_{2}$, demonstrate outward rectification in the $-100+100$ $\mathrm{mV}$ voltage ramp $(n=25)$. C, Representative single-channel current traces of cold-activated rTRPM8 in planar lipid bilayer obtained at $+100 \mathrm{mV}$ in the presence of $1 \%$ diC ${ }_{16} \mathrm{PI}(4,5) \mathrm{P}_{2}$, and summary of open probability of rTRPM8 at 22 and $11^{\circ}$ C, obtained at +100 and $-100 \mathrm{mV}(n=7)$. D. The rTRPM8 protein association with PIP strips. The full-length rTRPM8 protein, derived from bacterial expression, was incubated with the PIP strips overnight at $4^{\circ} \mathrm{C}$ in BSA-TTBS buffer and then immunoblotted with anti-CMR IgG. The figure demonstrates two separately developed PIP-strips: the left strip (control) shows the rTRPM8 protein binding to phosphoinositides in the absence of menthol, and the right strip (+ menthol) was obtained in the presence of $500 \mu \mathrm{m}$ menthol. The labeling indicated on the left corresponds to the left side of each strip; the labeling on the right corresponds to the right side of each strip. LPA, Lysophosphatidic acid; LPC, lysophosphocholine; Ptdlns, phosphatidylinositol; Ptdlns(3)P, phosphatidylinositol-3-phosphate; Ptdlns(4), phosphatidylinositol-4-phosphate; Ptdlns(5)P, phosphatidylinositol-5-phosphate; PE, phosphatidyethanolamine; PC, phosphatidylcholine; S1P, sphingosine-1-phosphate; Ptdlns(3,4), phosphatidylinositol-3,4-bi-phosphate; Ptdlns(3,5), phosphatidylinositol-3,5-bi-phosphate; Ptdlns(4,5), phosphatidylinositol-4,5-bi-phosphate; Ptdlns(3,4,5), phosphatidylinositol-3,4,5-tri-phosphate; PA, phosphatidic acid; PS, phosphatidylserine. A total of seven independent binding experiments were performed.

EGTA icilin-induced TRPM8 activity was significantly reduced (Fig. 6D) $(n=6)$.

\section{Discussion}

TRPM8 activation by cold

The molecular identity of the mammalian cold sensors has been a mystery until the demonstration of a cold-activated nonselective cation current in DRG neurons (Reid and Flonta, 2001) and the subsequent cloning of TRPM8 (McKemy et al., 2002; Peier et al., 2002). Cold activation of TRPM8 is characterized by high temperature dependence $\left(Q_{10}, \sim 24\right)$ and large changes both in enthalpy and entropy (Brauchi et al., 2004). Menthol primarily activates the channel by shifting its activation threshold to higher temperatures (McKemy et al., 2002). Temperature activation of TRPM8 also depends on the membrane voltage; at positive volt- ages, the channel is activated at warmer temperatures than at negative voltages (Voets et al., 2004). Genetic deletion of TRPM8 in mice shifts the temperature preference of the animals to colder temperatures (i.e., the animals are less sensitive to cold) (Bautista et al., 2007; Colburn et al., 2007; Dhaka et al., 2007). In the noxious cold-temperature range, however, the temperature preference of the animals is similar to that of wild-type animals, showing that other cold sensors may play a role in this temperature range.

TRPM8 is generally assumed to be directly activated by cold temperatures. Several recent articles, however, have suggested an alternative hypothesis. It was shown that cold activation of TRPM8 is inhibited by four different inhibitors of cytosolic PLA $\left(\mathrm{CPLA}_{2}\right)$ (Andersson et al., 2007), raising the possibility that the $\mathrm{CPLA}_{2}$ pathway is involved in cold activation of TRPM8. The 
same inhibitors also prevented activation of TRPM8 by icilin, but only moderately inhibited activation by menthol (Andersson et al., 2007). Accordingly, cPLA 2 inhibitors affected the icilin-induced, but not the menthol-induced cold hypersensitivity in vivo (Gentry et al., 2010). An independent study also showed partial inhibition of menthol-induced activation of TRPM8 by CPLA $_{2}$ inhibitors and by downregulation of $\mathrm{CPLA}_{2}$ with antisense RNA (Abeele et al., 2006).

In the current study, we demonstrate that cold activates the TRPM8-bilayer complex directly, without the involvement of any signaling cascades. We show that when exposed to cold, the purified TRPM8 undergoes a significant change in open probability (Fig. $2 \mathrm{~A}$ ). Following the highly temperature-dependent activation $\left(Q_{10}, \sim 40.1\right)$, TRPM8 thermodynamically stabilizes and exhibits regular diffusion gating rates $\left(Q_{10}, \sim 1.6\right)$ after the transition. The thermodynamic analysis of TRPM8 cold activation demonstrated that the transition in channel openings is accompanied by large enthalpy and entropy changes, but low free-energy change to ensure the reversibility of the process (Fig. 2C,D). This indicates that upon cold activation TRPM8 undergoes significant conformational rearrangements. The features of TRPM8 channel activation by cold in lipid bilayers are similar to those observed in a cellular system (Brauchi et al., 2004). They suggest the presence of a "temperature sensor" on TRPM8, which is responsible for the negative values of $\Delta S$ and net loss of entropically driven hydrophobic interactions in the closed-to-open transition induced by temperature. The process of temperature-dependent activation of TRPM8 thermodynamically is somewhat similar to a cold-induced protein denaturation (Pusch et al., 1997; Richardson et al., 2000), which is also characterized by large entropic and enthalpic changes, and relatively small changes in $\Delta G$. However, the temperature values that activate TRPM $8\left(8-26^{\circ} \mathrm{C}\right)$ are relatively mild to trigger peptide/protein denaturation, but nevertheless could be enough to induce conformational changes of nonproteinous molecules. Indeed, in our recent findings we have shown that TRPM8 exists in a supramolecular complex with two polymers, polyP and $\mathrm{PHB}$ (Zakharian et al., 2009). One of the polymers, PHB, possesses high temperature sensitivity and may participate in the temperature sensation of TRPM8. In this scenario, cold temperatures would induce substantial conformational changes in the flexible PHB backbone and consequently affect the conformation of the TRPM8 protein itself. It is noteworthy that most of the proteins that are known to be conjugated by $\mathrm{PHB}$ are temperature sensitive (Zakharian and Reusch, 2004, 2005). More studies are needed to unravel the complexity of this regulation.

The temperature threshold of TRPM8 activation was in the range of $18-23^{\circ} \mathrm{C}$ with the peak of transition observed at $\sim 18^{\circ} \mathrm{C}$, similar to that previously reported (Brauchi et al., 2004), and its temperature dependence was somewhat steeper than that observed in cells. It is likely that the fine tuning of temperature
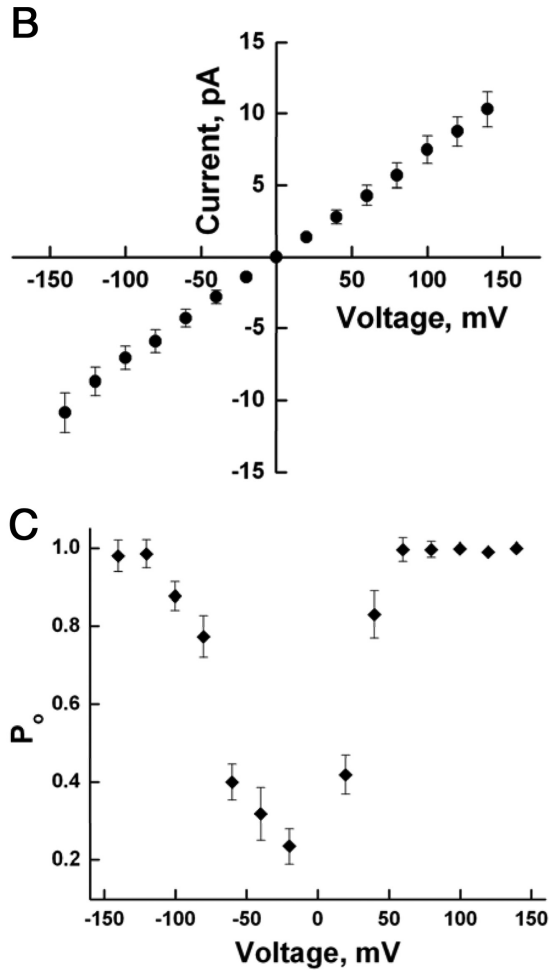

Figure 6. TRPM8 single channels activated with Icilin. $\boldsymbol{A}$, Representative current traces of TRPM8 channels activated with $1 \mu \mathrm{M}$

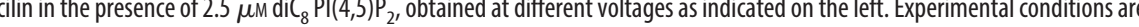
absence $\left(P_{0}=0.98 \pm 0.0025\right)$ or presence of EGTA $\left(P_{0}=0.022 \pm 0.015\right)$ shows the requirement of $\mathrm{Ca}^{2+}$ ions for the icilin a total of 13 experiments.

dependence of this channel is achieved by the cellular environment. Our data, however, demonstrate that the phenomenon of cold activation with steep temperature dependence is a property of the channel itself in the context of the bilayers and does not require activation of cellular signaling pathways. We have studied the purified TRPM8 in the context of the artificial lipid bilayers and argue that cold exerts its effects directly on the channel protein. It is also possible, however, that the primary effect of cold is to modify the physical properties of the lipid bilayers, which translates to conformational change in the channel protein leading to opening. Evaluating this possibility will require further experiments.

\section{TRPM8 activation by menthol}

Menthol has been used for centuries as a cooling agent both as a dietary supplement and as a local analgesic and antipruritic agent (Eccles, 1994; Patel et al., 2007). Its mechanism of action has been unknown until the cloning of TRPM8 (McKemy et al., 2002; Peier et al., 2002). A recent study identified residues responsible for menthol activation of TRPM8 (Bandell et al., 2006). It was proposed that the Y745 residue in the S2 segment is involved in menthol binding, and the L1009 in the coupling of menthol binding to channel opening (Bandell et al., 2006). These data are consistent with the widespread assumption that menthol activates TRPM8 directly, even though the binding of menthol to the channel was not demonstrated. Our data showing consistent menthol activation of the purified TRPM8 in artificial lipid bilayers together with our earlier report (Zakharian et al., 2009) serve as 
additional definitive proof for direct activation of the channel by menthol.

\section{Icilin activation of TRPM8}

Mutation of the same residues that eliminated menthol (but not cold) activation of TRPM8 also inhibited activation by icilin (Bandell et al., 2006). These data argue for similar molecular determinants for menthol and icilin in TRPM8 activation. On the other hand, there are abundant data showing differences between the two agents in activating TRPM8. Icilin activates TRPM8 with a much greater efficacy and potency, and it was shown that decreasing the extracellular $\mathrm{pH}$ to 6 eliminated icilin-induced and cold-induced, but not menthol-induced TRPM8 activation (Andersson et al., 2004). These data suggest that TRPM8 is activated by menthol and icilin by different mechanisms. Furthermore, icilin activation of TRPM8 was essentially eliminated by antagonists of cPLA 2 (Andersson et al., 2007), raising doubts that this cooling agent is a direct activator of TRPM8. Our data showing icilin-induced activation of the purified reconstituted TRPM8 demonstrate that icilin activates TRPM8 directly.

An additional difference between the effects of menthol and icilin is that the latter only activates TRPM8 if intracellular calcium concentrations are increased (Chuang et al., 2004). Many calcium-sensitive ion channels, such as intermediate and small conductance $\mathrm{Ca}^{2+}$-activated $\mathrm{K}^{+}$channels require an auxiliary protein, usually calmodulin, for modulation by calcium (Saimi and Kung, 2002). We show here that full activation of the purified TRPM8 by icilin requires the presence of calcium; thus, the calcium sensitivity of icilin activation in cellular systems is not due to an additional $\mathrm{Ca}^{2+}$-sensitive protein, but rather it is the property of the channel protein itself.

\section{Phosphoinositide regulation of TRPM8 gating}

$\mathrm{PI}(4,5) \mathrm{P}_{2}$ is a common regulator of many different ion channels (Hilgemann et al., 2001; Suh and Hille, 2008), including TRP channels (Nilius et al., 2008). The activity of most members of the TRPM and TRP vanilloid subfamilies depends on $\mathrm{PI}(4,5) \mathrm{P}_{2}$ (Rohacs, 2009). The molecular mechanism of $\mathrm{PI}(4,5) \mathrm{P}_{2}$ activation is best characterized in inwardly rectifying $\mathrm{K}^{+}$(Kir) channels (Logothetis et al., 2007). These channels are thought to be activated by $\mathrm{PI}(4,5) \mathrm{P}_{2}$ via interaction of the negatively charged head group of the phosphoinositide with positively charged residues in the cytoplasmic regions of the channels (Rosenhouse-Dantsker and Logothetis, 2007). This assumption is largely based on activation of the channel in excised patches by $\mathrm{PI}(4,5) \mathrm{P}_{2}$ (Sui et al., 1998) and direct binding of cytoplasmic fragment of the channel to $\mathrm{PI}(4,5) \mathrm{P}_{2}$ (Huang et al., 1998). It is well known, however, that excised patches may contain a variety of proteins, including $\mathrm{PI}(4,5) \mathrm{P}_{2}$-metabolizing enzymes (Huang et al., 1998; Nilius et al., 2006) guanine nucleotide-phosphorylating enzymes (Womack et al., 2000), and even cellular organelles (Ertel, 1990). Thus, it cannot be excluded that the effect of $\mathrm{PI}(4,5) \mathrm{P}_{2}$ in these experiments is due to the presence of an additional protein in the excised patches. Binding of $\mathrm{PI}(4,5) \mathrm{P}_{2}$ to isolated cytoplasmic fragments of the protein, again, does not necessarily mean that these interactions are responsible for the functional effects of the lipid. Further evidence on Kir channels is provided by systematically mutating positively charged residues, and demonstrating altered activation by $\mathrm{PI}(4,5) \mathrm{P}_{2}$ (Lopes et al., 2002) and altered binding of channel fragments to $\mathrm{PI}(4,5) \mathrm{P}_{2}$ (Huang et al., 1998). Altogether, the cumulative evidence on Kir channels is quite convincing that $\mathrm{PI}(4,5) \mathrm{P}_{2}$ activates the channels directly. Nevertheless, definitive evidence, the activation of a purified mammalian Kir channel in a reconstituted system, is lacking (Huang, 2007), and there are reports proposing that $\mathrm{PI}(4,5) \mathrm{P}_{2}$ activates some Kir channels indirectly through the cytoskeleton (Furukawa et al., 1996).

Knowledge on the molecular mechanism of the activation of TRP channels by $\mathrm{PI}(4,5) \mathrm{P}_{2}$ is a lot more cursory. It was shown that mutation of positively charged residues in the TRP domain of TRPM8 reduced the apparent affinity for $\mathrm{PI}(4,5) \mathrm{P}_{2}$ in a functional assay (i.e., excised patches) (Rohács et al., 2005). Mutation of the same residues in TRPM4, however, had no effect on $\mathrm{PI}(4,5) \mathrm{P}_{2}$ sensitivity; rather, mutations in a more distal domain affected $\mathrm{PI}(4,5) \mathrm{P}_{2}$ sensitivity (Nilius et al., 2006). Even though the C-terminal cytoplasmic fragments of several TRP canonical (TRPC) channels were shown to bind phosphoinositides (Kwon et al., 2007), the same study suggested that phosphoinositides modulate TRPC6 channels by modifying its interaction with calmodulin. Furthermore, the effects of $\mathrm{PI}(4,5) \mathrm{P}_{2}$ on TRP channels are often complex, with both inhibitory and activating effects having been described, sometimes even on the same channel (Rohacs, 2009). For TRPC4 $\alpha$ it was proposed that the inhibitory effect of $\mathrm{PI}(4,5) \mathrm{P}_{2}$ depended on the interaction of the channel with the actin cytoskeleton (Otsuguro et al., 2008). Thus, the case for direct activation of TRP channels by $\mathrm{PI}(4,5) \mathrm{P}_{2}$ has not been definitive so far.

In a recent study, we showed that menthol and cold activation of TRPM8 depends on the presence of $\mathrm{PI}(4,5) \mathrm{P}_{2}$ in lipid bilayers (Zakharian et al., 2009). Here we present evidence that TRPM8 function does not just depend on the presence of $\mathrm{PI}(4,5) \mathrm{P}_{2}$, but rather this phosphoinositide serves as a prime gating factor of the channel (Fig. 4). In the current study we also show that TRPM8 activation is specific to the $\mathrm{PI}(4,5) \mathrm{P}_{2}$ analog; other phosphoinositides, with more, less, or the same number of negative charges were less effective. This finding shows that the effect of $\mathrm{PI}(4,5) \mathrm{P}_{2}$ was not due to a nonspecific effect caused by the presence of an amphiphilic molecule in the bilayers, but rather was due to a specific interaction of the channel protein with $\mathrm{PI}(4,5) \mathrm{P}_{2}$. This specificity profile of activation is very similar to that observed in excised patches (Rohács et al., 2005).

Menthol has been shown to increase the sensitivity of TRPM8 to $\mathrm{PI}(4,5) \mathrm{P}_{2}$ activation in excised patches (Rohács et al., 2005). Here we have reproduced this effect in lipid bilayers and shown that menthol shifted the dose response for $\mathrm{PI}(4,5) \mathrm{P}_{2}$ to the left. This could happen either by enhanced effectiveness of the bound $\mathrm{PI}(4,5) \mathrm{P}_{2}$ to open the channel, or by enhanced binding of the lipid. To differentiate between these two possibilities, we show that binding of the full-length functional TRPM8 to phosphoinositides is enhanced by menthol.

The binding experiments were performed on the TRPM8 protein purified from a bacterial expression system. We show that this protein was functional; it was activated by cold and menthol in the presence of $\mathrm{PI}(4,5) \mathrm{P}_{2}$. These data demonstrate that the activity of TRPM8 does not depend on any post-translational modification specific to eukaryotic cells. The fact that TRPM8 can be purified in a functional form from bacteria may also help future studies aiming to obtain structural information on this protein.

Our data firmly establish $\mathrm{PI}(4,5) \mathrm{P}_{2}$ as a specific direct regulator of TRPM8 channels. In conclusion, our data provide definitive proof that cold, cooling agents, and phosphoinositides regulate TRPM8 channels directly. 


\section{References}

Andersson DA, Chase HW, Bevan S (2004) TRPM8 activation by menthol, icilin, and cold is differentially modulated by intracellular $\mathrm{pH}$. J Neurosci 24:5364-5369.

Andersson DA, Nash M, Bevan S (2007) Modulation of the cold-activated channel TRPM8 by lysophospholipids and polyunsaturated fatty acids. J Neurosci 27:3347-3355.

Bandell M, Dubin AE, Petrus MJ, Orth A, Mathur J, Hwang SW, Patapoutian A (2006) High-throughput random mutagenesis screen reveals TRPM8 residues specifically required for activation by menthol. Nat Neurosci 9:493-500.

Bautista DM, Siemens J, Glazer JM, Tsuruda PR, Basbaum AI, Stucky CL, Jordt SE, Julius D (2007) The menthol receptor TRPM8 is the principal detector of environmental cold. Nature 448:204-208.

Brauchi S, Orio P, Latorre R (2004) Clues to understanding cold sensation: thermodynamics and electrophysiological analysis of the cold receptor TRPM8. Proc Natl Acad Sci U S A 101:15494-15499.

Chuang HH, Neuhausser WM, Julius D (2004) The super-cooling agent icilin reveals a mechanism of coincidence detection by a temperaturesensitive TRP channel. Neuron 43:859-869.

Colburn RW, Lubin ML, Stone DJ Jr, Wang Y, Lawrence D, D'Andrea MR, Brandt MR, Liu Y, Flores CM, Qin N (2007) Attenuated cold sensitivity in TRPM8 null mice. Neuron 54:379-386.

Daniels RL, Takashima Y, McKemy DD (2009) Activity of the neuronal cold sensor TRPM8 is regulated by phospholipase $\mathrm{C}$ via the phospholipid phosphoinositol 4,5-bisphosphate. J Biol Chem 284:1570-1582.

Dhaka A, Murray AN, Mathur J, Earley TJ, Petrus MJ, Patapoutian A (2007) TRPM8 is required for cold sensation in mice. Neuron 54:371-378.

Eccles R (1994) Menthol and related cooling compounds. J Pharm Pharmacol 46:618-630.

Ertel EA (1990) Excised patches of plasma membrane from vertebrate rod outer segments retain a functional phototransduction enzymatic cascade. Proc Natl Acad Sci U S A 87:4226-4230.

Furukawa T, Yamane T, Terai T, Katayama Y, Hiraoka M (1996) Functional linkage of the cardiac ATP-sensitive $\mathrm{K}^{+}$channel to the actin cytoskeleton. Pflugers Arch 431:504-512.

Gentry C, Stoakley N, Andersson DA, Bevan S (2010) The roles of iPLA ${ }_{2}$, TRPM8 and TRPA1 in chemically induced cold hypersensitivity. Mol Pain 6:4.

Hilgemann DW, Feng S, Nasuhoglu C (2001) The complex and intriguing lives of PIP2 with ion channels and transporters. Sci STKE 2001:re19.

Huang CL (2007) Complex roles of PIP $_{2}$ in the regulation of ion channels and transporters. Am J Physiol Renal Physiol 293:F1761-F1765.

Huang CL, Feng S, Hilgemann DW (1998) Direct activation of inward rectifier potassium channels by $\mathrm{PIP}_{2}$ and its stabilization by Gbetagamma. Nature 391:803-806.

Kwon Y, Hofmann T, Montell C (2007) Integration of phosphoinositideand calmodulin-mediated regulation of TRPC6. Mol Cell 25:491-503.

Liu B, Qin F (2005) Functional control of cold- and menthol-sensitive TRPM8 ion channels by phosphatidylinositol 4,5-bisphosphate. J Neurosci 25:1674-1681.

Logothetis DE, Jin T, Lupyan D, Rosenhouse-Dantsker A (2007) Phosphoinositide-mediated gating of inwardly rectifying $\mathrm{K}(+)$ channels. Pflugers Arch 455:83-95.

Lopes CM, Zhang H, Rohacs T, Jin T, Yang J, Logothetis DE (2002) Alterations in conserved Kir channel-PIP $\mathrm{P}_{2}$ interactions underlie channelopathies. Neuron 34:933-944.

McKemy DD, Neuhausser WM, Julius D (2002) Identification of a cold receptor reveals a general role for TRP channels in thermosensation. $\mathrm{Na}-$ ture 416:52-58.

Nilius B, Mahieu F, Prenen J, Janssens A, Owsianik G, Vennekens R, Voets T (2006) The $\mathrm{Ca}^{2+}$-activated cation channel TRPM4 is regulated by phosphatidylinositol 4,5-biphosphate. EMBO J 25:467-478.

Nilius B, Owsianik G, Voets T (2008) Transient receptor potential channels meet phosphoinositides. EMBO J 27:2809-2816.

Otsuguro K, Tang J, Tang Y, Xiao R, Freichel M, Tsvilovskyy V, Ito S, Flockerzi V, Zhu MX, Zholos AV (2008) Isoform-specific inhibition of TRPC4 channel by phosphatidylinositol 4,5-bisphosphate. J Biol Chem 283:10026-10036.

Patel T, Ishiuji Y, Yosipovitch G (2007) Nocturnal itch: why do we itch at night? Acta Derm Venereol 87:295-298.

Peier AM, Moqrich A, Hergarden AC, Reeve AJ, Andersson DA, Story GM, Earley TJ, Dragoni I, McIntyre P, Bevan S, Patapoutian A (2002) A TRP channel that senses cold stimuli and menthol. Cell 108:705-715.

Pusch M, Ludewig U, Jentsch TJ (1997) Temperature dependence of fast and slow gating relaxations of ClC-0 chloride channels. J Gen Physiol 109:105-116.

Reid G, Flonta ML (2001) Physiology. Cold current in thermoreceptive neurons. Nature 413:480

Richardson JM 3rd, Lemaire SD, Jacquot JP, Makhatadze GI (2000) Difference in the mechanisms of the cold and heat induced unfolding of thioredoxin $h$ from Chlamydomonas reinhardtii: spectroscopic and calorimetric studies. Biochemistry 39:11154-11162.

Rohacs T (2009) Phosphoinositide regulation of non-canonical transient receptor potential channels. Cell Calcium 45:554-565.

Rohács T, Lopes CM, Michailidis I, Logothetis DE (2005) PI $(4,5) \mathrm{P}_{2}$ regulates the activation and desensitization of TRPM8 channels through the TRP domain. Nat Neurosci 8:626-634.

Rosenhouse-Dantsker A, Logothetis DE (2007) Potassium channel gating in the absence of the highly conserved glycine of the inner transmembrane helix. Channels (Austin) 1:189-197.

Saimi Y, Kung C (2002) Calmodulin as an ion channel subunit. Annu Rev Physiol 64:289-311.

Suh BC, Hille B (2008) $\mathrm{PIP}_{2}$ is a necessary cofactor for ion channel function: how and why? Annu Rev Biophys 37:175-195.

Sui JL, Petit-Jacques J, Logothetis DE (1998) Activation of the atrial KACh channel by the betagamma subunits of $\mathrm{G}$ proteins or intracellular $\mathrm{Na}^{+}$ ions depends on the presence of phosphatidylinositol phosphates. Proc Natl Acad Sci U S A 95:1307-1312.

Vanden Abeele F, Zholos A, Bidaux G, Shuba Y, Thebault S, Beck B, Flourakis M, Panchin Y, Skryma R, Prevarskaya N (2006) $\mathrm{Ca}^{2+}$-independent phospholipase $\mathrm{A}_{2}$-dependent gating of TRPM8 by lysophospholipids. J Biol Chem 281:40174-40182.

Voets T, Droogmans G, Wissenbach U, Janssens A, Flockerzi V, Nilius B (2004) The principle of temperature-dependent gating in cold- and heatsensitive TRP channels. Nature 430:748-754.

Womack KB, Gordon SE, He F, Wensel TG, Lu CC, Hilgemann DW (2000) Do phosphatidylinositides modulate vertebrate phototransduction? J Neurosci 20:2792-2799.

Zakharian E, Reusch RN (2004) Functional evidence for a supramolecular structure for the Streptomyces lividans potassium channel KcsA. Biochem Biophys Res Commun 322:1059-1065.

Zakharian E, Reusch RN (2005) Kinetics of folding of Escherichia coli OmpA from narrow to large pore conformation in a planar bilayer. Biochemistry 44:6701-6707.

Zakharian E, Thyagarajan B, French RJ, Pavlov E, Rohacs T (2009) Inorganic polyphosphate modulates TRPM8 channels. PLoS ONE 4:e5404. 